\title{
The Relationship between Obsessive-Compulsive Symptoms and Body Image in Boy and Girl High School Students
}

\author{
Bahman Kord Tamini*, Zeinab Rahdar, Farhad Kahrazei \\ Department of Psychology, University of Sistan and Baluchestan, Zahedan, Iran \\ Email: ${ }^{\text {bahmankord@ped.usb.ac.ir }}$
}

Received 22 June 2015; accepted 15 August 2015; published 18 August 2015

Copyright (C) 2015 by authors and Scientific Research Publishing Inc.

This work is licensed under the Creative Commons Attribution International License (CC BY).

http://creativecommons.org/licenses/by/4.0/

(c) (i) Open Access

\begin{abstract}
The present study aimed to examine the relationship between obsessive-compulsive symptoms and body image in boy and girl high school students. The sample consisted of 200 students of Zahedan city that were selected through cluster sampling method. To collect data, the Yale-Brown Obsessive-Compulsive Scale and Fisher's Body Image Inventory were applied. Obtained data were analyzed using the Pearson correlation coefficient, stepwise regression analysis and independent t-test. The results illustrated a significant relationship between obsessive-compulsive symptoms and body image. Results of stepwise regression analysis demonstrated that the variable of obsessive thoughts was a negative predictor of body image's overall score and the variable of compulsive was a positive predicator of overall score of body image. Results demonstrated that girl students obtained significantly higher mean scores on compulsion symptoms and total scores of OCD in comparison to boy students. But there were no significant differences with regard to students' gender on the scores of body image and obsession symptoms.
\end{abstract}

Keywords

Obsessive-Compulsive Symptoms, Body Image, Students

\section{Introduction}

Adolescence is the stage of dramatic and accelerating changes in the way that in a short time the yesterday's "Corresponding author.

How to cite this paper: Tamini, B. K., Rahdar, Z., \& Kahrazei, F. (2015). The Relationship between Obsessive-Compulsive Symptoms and Body Image in Boy and Girl High School Students. Psychology, 6, 1323-1330. 
children grow in stature of today's adults (Zargham, 1995, as cited in Pahlavan-Zadeh, Maghsoudi, Ghazavi, \& Habib-Pour, 2005). The contemporary world that is accompanied with progress and development which have been created in the context of rationalization has focused its attention more on the issues of human personality, issues that perhaps were considered trivial and unimportant about one-hundred years ago. Among the issues of human personality that has been less discussed is body image (Pasha, Naderi, \& Akbari, 2008).

The term of body image was first defined by Schilder (1920, as cited in Gleeson \& Fright, 2006) as an image of the body and physique which is created in our minds. This definition includes both the perception and the attitude. The scope of body image and concerns related to it have expanded so that an obsession, for many people especially young people, has been created and a lot of time and money is spent on thinking about and creating changes in body appearance (Green and Pritchard, 2003). When an individual is dissatisfied with his/her body image, he/she ventures for a change in his/her body image in order to approximate the actual body image to the ideal one. A component of body image is the behavioral component represented as body checking behaviors. Checking behaviors are similar to obsessive actions in which the individual refuses to find the main cause of his/her distress through mental rumination of his/her body shape and size (Rosen, 1997, as cited in Soroureh Azim-Zadeh, Razavieh, \& Moharreri, 2009). Intellectual concerns, doubt and superstitious beliefs are commonly seen in the daily life; however, when such thoughts intensify, so that the individual spends hours to unjustified actions such as checking the objects around his/her body, obsessive-compulsive disorder (henceforward OCD) is diagnosed (Mehrabi Zadeh Honarmand, Davoudi, Shokrkon, \& Najarian, 2007). Obsessive behaviors may be demonstrated as the obsessive-compulsive disorder representing a group of anxiety disorders characterized by frequent and recurrent obsession or compulsive behaviors which lead to high stress or obvious performance disorder (American Psychiatric Association, 1994; as cited in Jamali, Memarian, \& Kazem-Zadeh Otoufi, 2007). In the first place, body checking behaviors are behaviors for checking and controlling changes in the body and checking the shape of the body (Soroureh Azimzadeh et al., 2009).

Body checking behaviors include frequent weighting the body, frequent checking the changes in the body in a mirror, using special clothes to size the body, pressing different parts of the body to examine obesity, comparing body weight and body shape with others' (Fairburn, Cooper, \& Shafran, 2003). Body checking behaviors are carried out to examine the changes of the weight and body shape; however, an increase in such behaviors increases perception of body defects which leads to an increase in checking the weight leading to the formation of negative beliefs about body image and creation of an unnatural body image (Waller, Sines, Meyer, \& Mountford, 2008). The key factor in maintaining a poor body image is body checking behaviors which are focusing on a negative body image and negative self-perception (Fairburn et al., 2003). According to Caplan (2000), half of high school students are dissatisfied with their own body and this dissatisfaction turns to obsession leading them to become more mentally preoccupied with their body and thus try to change through going on a diet and doing exercise (Sadock, 2000).

Young people, as an important part of the community, have perceptions, feelings and impressions that need to be recognized. An adolescent's image of his/her body has consequences which create profound effects on the health of family and community and their development; however, paying too much attention to appearance and body prevents the adolescent from strengthening their other intellectual aspects and achieving academic success. Therefore, since the family is still considered as a major institution in training and socialization of individuals, paying attention to childhood socialization about body image can empower families to provide a suitable pattern for adolescents to perceive their body image in order to avoid considering their own effort and success depending on full attention to body image (Afrouz, 2007). Given the importance of adolescence, the young population, and the effect of body image satisfaction on mental health, considering the fact that early counseling and guidance can help prevent many of these problems or reduce their severity and with regard to the researcher's observations of the importance given by adolescents to their appearance, body, atrophy and obesity, changes in body, even in the normal process of growth and development have significant effects on their mental preoccupation leading to educational failure, isolation, lack of participation in social activities, eating disorders and low self-esteem, and since few studies have been conducted in this field in our country, the researchers aimed to study the relationship of obsessive-compulsive symptoms and body image among adolescents.

The findings of Phillips et al. (1995) and Ivarsson et al. (2006) showed that patients with fear of body dysmorphia have two sets of symptoms including obsessive symptoms related to appearance of the body (for example, image of a large body, the size of the face, sparse body and face hair) and compulsive symptoms related to physical appearance (for example, avoidance of mirror, checking different parts in a mirror, repeated compulsive 
behaviors related to make-up and covering the face) (as cited in Basak-Nejad \& Ghaffari, 2007). In addition, Thompson and Stice (2001), Keery, Van den Berg and Thompson (2004) reported that there was a relationship between fear of body dysmorphia and obsessive behaviors, so that in these individuals, types of obsessivecompulsive behaviors are formed to find the mental defect, for example, repeated checking in front of a mirror to find pimples or repeated examination of the body to find freckles or pimples. The results of Hanigman, Philips and Castle (2004) and Thompson and Smolak (2001) suggested that fear of body dysmorphia or dissatisfaction with physical appearance was correlated with psychiatric disorders (for example, depression, obsession, social phobia, anxiety and drug abuse). According to Williamson, White, York-Crowe and Stewart (2004), body checking behaviors can intensify concerns about the shape and size of the body and lead to negative body image and strengthening behavioral disorder patterns. Neziroglu, et al. (2003) found that body dysmorphic disorder and dissatisfaction were significantly correlated with body image and OCD (as cited in Rabiei, Salahian, Bahrani \& Palahang, 2011). Studies conducted by Stice and Shaw (2003) and Stice and Whitenton (2002) showed that dissatisfaction with body image was associated with emotional distress, having excessive obsession thoughts about the appearance, depression, and poor self-esteem. Brynska (1997), examining OCD in children and adults, showed that the number of female adolescents stricken by obsession was more than males, and the prevalence of this disorder in males and females was 12.1 and 10.7, respectively. In another study carried out by Geller et al. (1998), the ratio of the prevalence of OCD in males to females was estimated about 3/2. Ismail (1998, as cited in Shams et al., 2007) asserted that the prevalence of obsession in females was higher compared to males. Roote (2002) conducted a research on gender differences in body image and its relationship with self-esteem in young people and found that body image varied according to gender (as cited in Noorbakhsh \& Hassanpour, 2004). Various studies indicated females' very high and harmful sensitivity to body image (Thomson, Heinberg and Altab, 1994, as cited in Amidi et al., 2006). Research of Duncan et al. (2006) showed that in general, female adolescents, compared to male counterparts, were more dissatisfied with their body shape and size (as cited in Hatata, Awaad, El Sheikh, \& Refaat, 2009). Hatata et al. (2009), examining the dissatisfaction with body image and its relationship with psychiatric symptoms, eating beliefs, and self-esteem in female adolescents, found that female adolescents who were dissatisfied with their body image had a higher level of OCD.

Bask-Nejad and Ghaffari (2007) conducted a study to examine the relationship between fear of body dysmorphia and psychological disorders of university students and indicated that obsessive-compulsive behavior was the best predictor of fear of body dysmorphia. Soroureh Azimzadeh et al. (2009), evaluating the relationship of disordered eating with body checking behaviors of Arsanjan Islamic Azad University students, showed that body checking behaviors in females could be seen far more than males. These checking behaviors occur as a result of paying too much attention to the body and body dissatisfaction. In the study of Pahlavan-Zadeh et al. (2005) carried out on satisfaction with body image and BMI in adolescents, the results showed that the average satisfaction with body image in females was lower than that in males. Bahram, Shafizadeh and Sanatkaran (2002) compared active and inactive adult body image subscales and its relationship with body composition and type of configuration and concluded that there was no significant difference between the genders considering their body image. The results of a study conducted by Touzandeh Jani and Kamal-Pour (2004), examining obsessive thoughts coping methods on 31 patients with OCD, found that gender was not an effective factor in OCD and the two genders indicated no difference considering their mean scores on OCD scales. According to the theoretical and experimental research studies mentioned, the aim of this study was to investigate the relationship between OCD symptoms and body image in boy and girl high school students of Zahedan city. Thus, the following questions have been raised:

1) Is there any significant relationship between the dimensions of OCD and body image in boy and girl students?

2) Is there any significant difference between boy and girl students' mean scores on OCD and body image?

\section{Research Method}

This was a cross-correlational and descriptive study. The population included 2300 male and female students studying in public high schools of Zahedan in the 2012-2013 academic year. In the present study, random cluster sampling was used. According to the Krejcie and Morgan's formula of sample size and given the number of questionnaires and variables, 200 students, including 100 females and 100 males were selected the mean age and standard deviation of students was 16 and 6.48, respectively. Initially, four schools were selected from different parts of the city ( 2 female and 2 male high schools). Then, after visiting each school, four classes each contain- 
ing 25 students were randomly selected and the questionnaires were distributed among students to be completed. Before distribution the tools all scales were well translated into the Persian language. Permission letters were obtained from the department of psychology, University of Sistan and Baluchestan to Education and Training Organization for distributing the scales among the boy and girl high school students, and scales were given to the students with adequate instructions on how to respond to the questions. The students were also assured that their participation in the study was voluntary and their responses would remain confidential and used for the research purpose only.

\section{Tools Used}

\subsection{The Yale-Brown Obsessive-Compulsive Scale}

This scale, which was developed by Goodman et al. (1989) is a semi-structured interview aims at assessing symptoms, severity and response to treatment of OCD. The Yale-Brown Symptoms List evaluates obsessions and compulsions separately and entails more than fifty species of common obsession and compulsion including obsession about aggression, pollution, sexual affairs, compulsion on cleanliness, checking, arrangement, collecting and storing. The list contains symptoms of OCD in Diagnostic Statistical Manual. The cut-off point of the scale is 17 (Dadfar, Bolhari, Malakouti, \& Bayan-Zadeh, 2001). The scale has 10 items, 5 of which are designed to assess obsession and the other 5 items are intended to assess compulsion. The rating of the scale is performed on a five-point Likert-type scale from 1 (no symptoms) to 5 (very severe) related to 1 -severity of symptoms, 2-frequency of symptoms, 3-duration of symptoms, 4-level of anxiety and interference of symptoms with daily life, and 5-resistance to this process, in two dimensions of obsession and compulsion. Data related to the validity and reliability of this scale showed that the inter-rater reliability coefficient and internal consistency (alpha) of the scale examined on 40 patients were 0.98 and 0.89 , respectively. Convergent validity of the test using Clinical Global Impression of Obsessive-Compulsive Syndrome at baseline was 0.97. Test-retest reliability of the scale within 2 weeks was 0.84 and its differential reliability with the Beck's Depression Inventory and the Hamilton's Rating Scale for Anxiety was 0.59 and 0.64, respectively (Goodman et al., 1989). Dadfar, Bolhari, Malakouti and Bayan-Zadeh (2001), measuring the reliability of the Yale-Brown scale using test-retest reliability coefficient in the two-week period, indicated that its reliability was 0.84 . In this study, Cronbach's alpha coefficient was used. The alpha value for obsession, compulsion and the total scale was 0.81 , 0.83 and 0.88 , respectively.

\subsection{Fisher's Body Image Inventory}

The body image inventory was developed by Fisher in 1970. It contains 46 items. Each item is rated on a Likert-type scale ranges from 1 to 5 ( 1 = very dissatisfied, $2=$ dissatisfied, $3=$ moderate, $4=$ satisfied, $5=$ very satisfied). A score of 46 in this test represents a disorder and a score higher than 46 (maximum 230) shows no disorder. Areas measured by this test include:

1) Head and face: items 1-3-4-13-17-26-30-31-34-35-43-44.

2) Upper extremities: items 16-21-23-24-25-33-36-38-40-42.

3) Lower extremities: items 2-5-9-15-28-46.

4) Overall features of the body: items 6-7-8-10-11-12-14-18-19-20-22-27-29-32-37-39-41-45.

The validity of this test was explored by Yazdanjou (2000) in Iran. To standardize the test, 99 students in the first, second and third grades of high school were selected and were test-retested in an interval of 10 days. The correlation coefficient calculated on the implementation of the first and second administration by Pearson's test for the first, second, and third grade students was $0.81,0.84$, and 0.87 and for students' total score, it was 0.84 . Given the significance level ( $p<0.0001$ ) with 99.99\% confidence level, it could be accepted that there was a significant correlation between test scores obtained on the first run and test scores obtained on the second run of the test. In the present study, the reliability was measures using Cronbach's alpha coefficient for the dimensions of head and face, upper extremities, lower extremities, and overall features, which was 0.87, 0.88, 0.90, and 0.96, respectively.

\section{Results}

To analyze the data Pearson correlation coefficient, stepwise regression, and independent t-test were used and 
results are given in the below tables.

1) Is there any significant relationship between the dimensions of OCD and body image in boy and girl students? To answer to the first question Pearson correlation coefficient and stepwise regression was used and results are presented in the Table 1 and Table 2.

Results of Table 1 indicate that there are negative and significant correlations between body image and upper extremities of the body image $(r=-0.203, p=0.004)$, compulsion $(r=-0.140, p=0.048)$ and the total score of obsession $(r=-0.177, p=0.0 .12)$. Moreover, the total scores of body image is negatively and significantly correlated with obsession $(\mathrm{r}=-0.157, p=0.028)$.

According to Table 2, to investigate the predictive power of the total score of body image based on OCD dimensions, stepwise regression analysis was used. Results indicated that in the first step, obsession and then compulsion entered into the regression equation and explained $2.5 \%$ and $2 \%$ of the variance of total score of body image, respectively. Obsession had a significant negative relation (Beta $=-0.380, p=0.004$ ) and compulsion had a significant positive relation (Beta $=0.264, p=0.046$ ) with the total score of body image. Obsession and compulsion were respectively negative and positive predictors of the total score of body image.

2) Is there any significant difference between boy and girl students' mean scores on OCD and body image? To compare the mean scores of OCD between boy and girl students independent t-test was applied and results are presented in the Table 3 .

The results of Table 3 illustrates that there is significant differences for boy $(M=10.45$, SD $=3.804)$ and girl students [M $=11.72, \mathrm{SD}=4.071 ; \mathrm{t}(198)=-2.269, p<0.05]$ on compulsion symptoms and there was significant difference for boy $(\mathrm{M}=21.73$, $\mathrm{SD}=6.739)$ and girl students $[\mathrm{M}=23.66, \mathrm{SD}=7.138$; $\mathrm{t}(198)=-1.96, p<0.05]$ on total scores of OCD; girl students obtained significantly higher mean scores on compulsion symptoms and total scores of OCD in comparison to boy students. But there were no significant differences with regard to students' gender on the scores of body image and obsession symptoms.

\section{Discussion and Conclusion}

The main objective of this study was to examine the relationship between obsessive-compulsive symptoms and body image in boy and girl high school students in Zahedan. The results indicated that the overall dimensions of OCD had a significant negative relationship with body image. In addition, it was revealed that obsession and compulsion were negative and positive predictors of body image, respectively. In the present study, it was revealed that adolescents had more obsessions about their upper extremities, compared to other extremities, and performed more checking behaviors. The more these obsessions occur, the more dissatisfied the adolescent will be with his/her body image. These findings are consistent with the results of Phillips et al. (1995), Ivarsson et al. (2006), Thompson and Stice (2001), Kerry, et al. (2004), Hanigman et al. (2004), Thompson and Smolak (2001), Williamson et al. (2004), Neziroglu et al. (2003), Stice and Shaw (2003), Stice and Whitenton (2002), Hatata et al (2009), Basak-Nejad and Ghaffari (2007) and Soroureh Azimzadeh et al. (2009). It was also revealed that

Table 1. Correlation coefficients of different dimensions of obsession with body image.

\begin{tabular}{cccc}
\hline Variable & Obsession & Compulsion & Total score OCD \\
\hline Head and face & -0.080 & -0.016 & -0.048 \\
Upper extremities & $-0.203^{* *}$ & $-0.140^{*}$ & $-0.177^{*}$ \\
Lower extremities & -0.050 & 0.029 & -0.008 \\
Overall features & -0.109 & -0.022 & -0.065 \\
Body image & $-0.157^{*}$ & -0.057 & -0.109 \\
\hline
\end{tabular}

${ }^{* *} p<0.01, \stackrel{*}{p}<0.05$.

Table 2. Results of stepwise regression analysis of body image based on OCD dimensions.

\begin{tabular}{ccccccccc}
\hline Variable & $\mathrm{R}$ & $\mathrm{R}^{2}$ & $\Delta \mathrm{R}^{2}$ & $\mathrm{~B}$ & $\mathrm{SD} . \mathrm{E}$ & Beta & $\mathrm{T}$ & Sig. \\
\hline Obsession & 0.157 & 0.025 & 0.025 & -0.577 & 0.199 & -0.380 & -2.894 & 0.004 \\
Compulsion & 0.211 & 0.044 & 0.020 & 0.359 & 0.179 & 0.264 & 2.012 & 0.046 \\
\hline
\end{tabular}


Table 3. Results of independent samples t-test on OCD dimensions and body image between male and female students.

\begin{tabular}{|c|c|c|c|c|c|c|c|}
\hline Variable & Gender & $\mathrm{N}$ & Mean & SD & t value & $\mathrm{df}$ & Sig. \\
\hline Head and face & $\begin{array}{l}\text { Boy } \\
\text { Girl }\end{array}$ & $\begin{array}{l}100 \\
100\end{array}$ & $\begin{array}{l}49.21 \\
48.99\end{array}$ & $\begin{array}{l}7.556 \\
8.389\end{array}$ & 0.195 & 198 & 0.846 \\
\hline Upper extremities & $\begin{array}{l}\text { Boy } \\
\text { Girl }\end{array}$ & $\begin{array}{l}100 \\
100\end{array}$ & $\begin{array}{l}40.84 \\
39.98\end{array}$ & $\begin{array}{l}6.894 \\
7.262\end{array}$ & 0.857 & 198 & 0.392 \\
\hline Lower extremities & $\begin{array}{l}\text { Boy } \\
\text { Girl }\end{array}$ & $\begin{array}{l}100 \\
100\end{array}$ & $\begin{array}{l}24.14 \\
23.83\end{array}$ & $\begin{array}{l}4.321 \\
4.445\end{array}$ & 0.500 & 198 & 0.618 \\
\hline Overall features & $\begin{array}{l}\text { Boy } \\
\text { Girl }\end{array}$ & $\begin{array}{l}100 \\
100\end{array}$ & $\begin{array}{l}72.48 \\
69.53\end{array}$ & $\begin{array}{l}11.604 \\
11.716\end{array}$ & 1.789 & 198 & 0.075 \\
\hline Body image & $\begin{array}{l}\text { Boy } \\
\text { Girl }\end{array}$ & $\begin{array}{l}100 \\
100\end{array}$ & $\begin{array}{l}186.67 \\
181.78\end{array}$ & $\begin{array}{l}28.484 \\
29.603\end{array}$ & 1.186 & 198 & 0.237 \\
\hline Obsession & $\begin{array}{l}\text { Boy } \\
\text { Girl }\end{array}$ & $\begin{array}{l}100 \\
100\end{array}$ & $\begin{array}{l}11.28 \\
12.03\end{array}$ & $\begin{array}{l}3.763 \\
3.632\end{array}$ & -1.431 & 198 & 0.145 \\
\hline Compulsion & $\begin{array}{l}\text { Boy } \\
\text { Girl }\end{array}$ & $\begin{array}{l}100 \\
100\end{array}$ & $\begin{array}{l}10.45 \\
11.72\end{array}$ & $\begin{array}{l}3.804 \\
4.071\end{array}$ & $-2.269^{*}$ & 198 & 0.024 \\
\hline Total scores of OCD & $\begin{array}{l}\text { Boy } \\
\text { Girl }\end{array}$ & $\begin{array}{l}100 \\
100\end{array}$ & $\begin{array}{l}21.73 \\
23.66\end{array}$ & $\begin{array}{l}6.739 \\
7.138\end{array}$ & $-1.960^{*}$ & 198 & 0.05 \\
\hline
\end{tabular}

there was a significant negative correlation between obsessive-compulsive behaviors and body image. Those who have a poor body image suffer from two sets of symptoms including obsessive symptoms related to appearance of the body such as an image of a large body or the size of the face, and compulsive symptoms related to physical appearance such as checking different parts in a mirror.

It was also shown that obsession was the best predictor of negative body image and adolescents and young people, who are too obsessed and worried, are less satisfied with their body image. The reason of this undesirable body image is that the individuals with OCD have a perfectionist personality, which makes them pay too much attention to details of the appearance, and permanent and inescapable preoccupation with their real or imagined flaws in their appearance and assess their body image negatively. The reason that adolescents, more than other age groups, have obsession and as a result poor body image is that adolescence pay more attention to their body shape and appearance, thinness and obesity compared to other age groups and changes in the body even during the normal process of development, preoccupies them, and these obsessions can adversely affect their body image. On the other hand, under socio-cultural pressures and a variety of media propaganda about beauty and fitness, people unremittingly evaluate their appearance to attain what the community consider an ideal body, but since they cannot attain enough satisfaction of the ideal body compared with the ideal body imposed by the community, they are forced to resort to behaviors that conceal this undesirable body image to be released from all these permanent concerns and worries.

Accordingly, in this study, girl students' scores on compulsion and their total score on OCD were higher compared to boys. These findings are consistent with the results of Brynska (1997), Ismail (1998), and Soroureh Azimzadeh, et al. (2009) who found that the prevalence of obsession in females is more than that in males. However, this finding is inconsistent with the results of Geller et al. (1998) who estimated the ratio of the prevalence of OCD in males to females as 3/2, and Touzandeh Jani and Kamal-Pour (2004) who found that gender was not an effective factor in OCD and that the two genders indicated no differences considering their mean scores on OCD scales. In addition, the current study revealed that no significant difference was observed with regard to gender in obsession. The reason may be the importance given to appearance by both boy and girl adolescents in today's society. However, since girl adolescents pay more attention to their appearance and beauty is more important to them than boys, girls spend more hours exploring their extremities and body which may turn into obsessive behaviors (such as looking in the mirror and make-up). On the other hand, girl adolescents, due to experiencing sensitive age and their sex-related status, generally regard their appearance more; therefore, when their general concerns about their appearance are evaluated, their sensitivity escalates. Another reason for the difference between the genders in OCD in general can be noted in this way that in Iran country, usually the responsibilities considered for females and males are different.

Another result of the present study is that there was no significant difference between boy and girl students 
considering their body image. This finding was inconsistent with the results of Ruth (2002), Thomson, Heinberg and Altab (1994), Duncan et al. (2006) and Phalavan-Zadeh et al. (2005) who indicated that body image is related to gender and females have more negative attitudes towards their bodies compared to males. However, it is in line with the findings of Bahram et al. (2002) who concluded that there was no significant difference between the genders with regard to their body image. The reason may be attributed to the unique socio-cultural structure of Zahedan. Clearly, since mass media and the outer environment exhibit less fashion and fewer completions, and in addition, since females wear hijab, they feel less anxiety for their presence in the community. Therefore, the difference was not significant. This difference that why in previous research study, such a difference was significant could be attributed to the fact that due to complex and confusing social implications and expectations of females regarding their role in the society, they pay much more attention to their appearance. Another explanation is that one of the personal criteria of females which can be judged by males is her beauty and appearance. On the other hand, in today's society, females try to be thin because they think this will help them look more attractive. Thus, they regard their body image more than males do. Maturation in adolescents is associated with features which may cause them to feel less praised, and changes may occur in their physiques that escalate their dissatisfaction and obsession. During these changes, the adolescent compares his/her appearance and body to others, and in most cases, this leads to dissatisfaction. On the other hand, due to peer pressure, educational issues, high school period is one of the most sensitive and the most stressful periods of education; thus, this research examined adolescents' intellectual involvement with their body image. The limitations and suggestion of the study are listed below:

- Since this study was conducted only on students in Zahedan, its validity was at risk and it should be cautiously generalized.

- According to the findings of the study, it is suggested that, in future research, the impact of factors affecting body image, i.e. peers, family, fashion, mass media, etc. be investigated.

- It is recommended that the same research design be used on other groups, such as university, pre-university and junior high school students.

\section{References}

Afrouz, Gh. A. (2007). Introduction to Psychology and Training Children and Adolescents (11th ed.). Tehran: Parents and Teachers Publication.

Amidi, M., Ghofranipour, F. A., \& Hosseini, R. (2006). The Relationship between Body Image, Dissatisfaction and BMI in Female Adolescents. Behavioral Sciences Research Journal, 4, 59-65.

Bahram, A., Shafizadeh, M., \& Sanatkaran, A. (2002). Comparison of Subscales Body Image in Active and Inactive Adults and Its Relationship with Type of Body and Body Composition. Research in Sport Sciences, 1, 13-28.

Basak-Nejad, S., \& Ghaffari, M. (2007). The Relationship between Fear of Body Dysmorphia and Psychological Disorders of University Students. Journal of Behavioral Sciences, 2, 187-179.

Brynska, A. (1997). Obsessive Compulsive Disorder in Children and Adolescents: Literature Review. Part 1. Psychiatria Polska, 31, 417-428.

Dadfar, M., Bolhari, J., Malakouti, K., \& Bayan-Zadeh, A. (2001). Prevalence of Symptoms of Obsessive-Compulsive Disorder. Journal of Behavior and Thought, 7, 27-32.

Fairburn, C. G., \& Harrison, P. (2003). Eating Disorders. Lancet, 361, 407-416. http://dx.doi.org/10.1016/S0140-6736(03)12378-1

Geller, D. A., \& Biederman, J., Jones, J., Shapiro, S., Schwartz S., \& Park, K. S. (1998). Obsessive-Compulsive Disorder in Children and Adolescents: A Review. Harvard Review of Psychiatry, 5, 260-273. http://dx.doi.org/10.3109/10673229809000309

Gleeson, K., \& Fright, H. (2006). Constructing Body Image. Journal of Health Psychology, 11, 79-90. http://dx.doi.org/10.1177/1359105306058851

Goodman, W. K., Price, L. H., Rasmussen, S. A., Mazure, C., Fleischmann, R. L., Hill, C. L., Hininger, G. R., \& Charney, D. S. (1989). The Yale-Brown Obsessive Compulsive Scale, I: Development, Use, and Reliability. Archives of General Psychiatry, 46, 1006-1011. http://dx.doi.org/10.1001/archpsyc.1989.01810110048007

Green, P., \& Pritchard, M. (2003). Predictors of Body Image Dissatisfaction in Adult Men and Women. Social Behavior Personality, 31, 215-222. http://dx.doi.org/10.2224/sbp.2003.31.3.215

Hanigman, R., Philips, K., \& Castle, D. J. (2004). A Review of Psychosocial Outcomes for Patients Seeking Cosmetic Surgery. Plastic and Reconstructive Surgery, 113, 1229-1237. http://dx.doi.org/10.1097/01.PRS.0000110214.88868.CA 
Hatata, H., Awaad, M., El sheikh, M., \& Refaat, G. (2009). Body Image Dissatisfaction and Its Relationships with Psychiatric Symptomatology, Eating Beliefs and Self Esteem in Egyptian Female Adolescents. Current Psychiatry, 16, 35-45.

Jamali, A., Memarian, N., \& Kazem-Zadeh Otoufi, M. (2007). The Prevalence of Obsessive-Compulsive Symptoms, and Some Demographic Factors Associated with It among Junior High School Students in Tehran in 2005. Rehabilitation Journal, 1, 61-66.

Keery, H., Van den Berg, P., \& Thampson, J. K. (2004). An Evaluation of the Tripartite Influence of Body Dissatisfaction and Eating Disturbance with Adolescent Girls. Body Image, 1, 37-251. http://dx.doi.org/10.1016/j.bodyim.2004.03.001

Mehrabi Zadeh Honarmand, M., Davoudi, I., Shokrkon, H., \& Najarian, B. (2007). The Role of Cognitive and Personality Traits, Family History and Psychological Pressure in Predicting Obsessive-Compulsive Disorder. Journal of Psychology, Shahid Chamran University of Ahvaz, 3, 27-56.

Noorbakhsh, P., \& Hassanpour, G. (2004). Comparison of Self-Esteem and Self-Concept of Athlete and Non-Athlete High School Male High School Students in Ahwaz and Their Relationship with Students' Academic Achievement. Journal of Harkat, 21, 19-32.

Pahlavan-Zadeh, S., Maghsoudi, J., Ghazavi, Z., \& Habib-Pour, Z. (2005). Satisfaction with Body Image and BMI in Adolescents. Behavioral Sciences Research Journal, 3, 39-44.

Pasha, G. R., Naderi, F., \& Akbari, S. (2008). Comparison of Body Image, Body Mass Index, General Health, and SelfConcept among People Who Do Cosmetic Surgery, Cosmetic Surgery Applicants and Ordinary People in Behbahan. New Findings in Psychology, 2, 61-80.

Rabiei, M., Salahian, A., Bahrani, F., \& Palahang, H. (2011). Construction and Validation of Body Dysmorphic Meta-Assessment Questionnaire. Journal of Mazandaran University of Medical Sciences, 21, 43-52.

Shams, G., Karam Ghadiri, N., Ismaleeli Torkanpouri, Y., Amini, H., Ebrahimkhani, N., Naseri Befroni, A., \& Paiedar Ardakani, H. (2007). The Prevalence of Obsessive-Compulsive Symptoms in Adolescents and Its Comorbidity with Other Psychiatric Symptoms. Cognitive Sciences News, 9, 50-59.

Soroureh Azim-Zadeh, B., Razavieh, A., \& Moharreri, M. R. (2009). The Relationship between Body Checking Behaviors with Turbulent Eating among Arsanjan University Students. Journal of Applied Psychology, Islamic Azad University of Khorasgan, 42, 124-148.

Stice, E., \& Shaw, H. (2003). Prospective Relations of Body Image, Eating, and Affective Disturbances to Smoking Onset in Adolescent Girls: How Virginia Slims? Journal of Consulting and Clinical Psychology, 71, 129-135. http://dx.doi.org/10.1037/0022-006X.71.1.129

Stice, E., \& Whitenton, K. (2002). Risk Factors for Body Dissatisfaction in Adolescent Girls: A Longitudinal Investigation. Developmental Psychology, 38, 669-678. http://dx.doi.org/10.1037/0012-1649.38.5.669

Thompson, J. K., \& Smolak, L. (2001). Body Image, Eating Disorders and Obesity in Youth. Assessment, Prevention and Treatment, 50, 1-19.

Thompson, J. K., \& Stice, E. (2001). Thin Ideal Internalization Mounting Evidence for a New Risk Factor for Body Image Disturbance and Eating Pathology. Current Direction in Psychological Science, 10, 181-183. http://dx.doi.org/10.1111/1467-8721.00144

Touzandeh Jani, H., \& Kamal-Pour, N. (2004). How to Deal with Obsessive Thoughts and Actions. Journal of Mental Health, 6, 1-11.

Waller, G., \& Sines, J., \& Meyer, C., \& Mountford, V. (2008). Body Checking in the Eating Disorders: Association with Narcissistic Characteristics. Eating Behaviors, 9, 163-169. http://dx.doi.org/10.1016/j.eatbeh.2007.07.004

Williamson, D. A., White, M. A., York-Crowe, E., \& Stewart, T. M. (2004). Cognitive-Behavioral Theories of Eating Disorders. Behavior Modification, 28, 711-738. http://dx.doi.org/10.1177/0145445503259853

Yazdanjou, F. (2000). Relationship between Body Image and the Level of Compatibility of Female High School Students in Mashad. Unpublished M.A Dissertation of Counseling Psychology, School of Management and Planning of the Ministry of Education. 